\title{
Congestive heart failure and converting enzyme inhibition: failure of current prognostic criteria for predicting subsequent renal insufficiency
}

\author{
Jonathan Odum, Peter Carson ${ }^{1}$ and Gavin Russell
}

Department of Nephrology, North Staffordshire Royal Infirmary, Princes Road, Hartshill, Stoke on Trent, Staffordshire ST4 7LN, and ${ }^{1}$ Department of Cardiology, City General Hospital, Stoke on Trent, Staffordshire, UK.

\begin{abstract}
Summary: Angiotensin-1-converting enzyme inhibitors have an effective and established role in the treatment of patients with congestive heart failure. However, a small number of such patients will subsequently develop renal insufficiency. These patients may be identified prior to, or shortly after, commencement of therapy by recognized criteria. This report describes 4 patients with congestive heart failure who developed severe renal insufficiency secondary to either enalapril or captopril therapy in the absence of any currently recognized predisposing factors. One patient died.
\end{abstract}

\section{Introduction}

Angiotensin-1-converting enzyme (ACE) inhibition is a well-established therapy, in combination with diuretics, in the treatment of congestive heart failure. However, a small number of patients will develop renal functional deterioration subsequently. It has been suggested that the development of renal failure in these patients is largely predictable, and has been the subject of a recent 'state of the art' paper by Packer. ${ }^{1}$ Indicators as to which patients will develop renal insufficiency are: (1) excessive reduction in blood pressure by ACE inhibition; (2) intravascular volume and/or sodium depletion prior to ACE inhibition; (3) pre-existing hyponatraemia; (4) bilateral renal artery stenosis; (5) diabetic patients.

We report 4 patients referred to the renal unit after development of severe renal insufficiency secondary to converting enzyme inhibition in the absence of any of the above predisposing factors. One patient died.

\section{Case 1}

A 64 year old women was diagnosed as having severe bi-ventricular heart failure in 1985 . She underwent mitral valve replacement in April of the same year. In October 1986 she was admitted to hospital with deteriorating congestive cardiac failure of uncertain cause. Her medication consisted of

Correspondence: J. Odum, M.R.C.P.

Accepted: 15 October 1990 frusemide $120 \mathrm{mg}$ daily, amiloride $10 \mathrm{mg}$ daily, digoxin and warfarin. Clinically, her jugular venous pressure (JVP) was raised, she had pitting sacral and ankle oedema, and mild pulmonary oedema. Her blood pressure was $145 / 85 \mathrm{mmHg}$. On admission her serum biochemistry showed urea $7 \mathrm{mmol} / \mathrm{l}$, sodium $138 \mathrm{mmol} / 1$, potassium 4.1 $\mathrm{mmol} / \mathrm{l}$ and creatinine $92 \mu \mathrm{mol} / \mathrm{l}$. She was commenced on enalapril $2.5 \mathrm{mg}$ daily in addition to the above. She was discharged after 7 days on this medication. Serum electrolytes remained normal. In May 1987 her enalapril was increased to $10 \mathrm{mg}$ daily in view of worsening symptoms, with no change in diuretic dosage. Serum urea and electrolytes were normal the same day.

On review in February 1988, symptomatically she was well and clinically there were no signs of heart failure. Her JVP was visible at $45^{\circ}$ and blood pressure was $125 / 80 \mathrm{mmHg}$ lying and standing. However, her renal function had markedly deteriorated with a serum urea of $36.9 \mathrm{mmol} / \mathrm{l}$, creatinine $160 \mu \mathrm{mol} / \mathrm{l}$ and potassium $4.0 \mathrm{mmol} / \mathrm{l}$. Enalapril was discontinued. Within 1 week her renal function had returned to normal. Subsequently, a diethyltriaminepentacetic acid (DTPA) isotope renogram showed no evidence of renovascular disease. She is not diabetic and has never had proteinuria.

\section{Case 2}

A 59 year old non-diabetic woman was admitted to hospital in 1987 with congestive cardiac failure of ischaemic origin. She was commenced on fruse- 
mide $80 \mathrm{mg}$ daily and amiloride $10 \mathrm{mg}$ daily. However, after 7 days her symptoms persisted, and she continued to exhibit a raised JVP and peripheral oedema. Blood pressure was $130 / 70 \mathrm{mmHg}$. Plasma urea and electrolytes at this time were normal. She was commenced on enalapril $2.5 \mathrm{mg}$ daily with the frusemide and amiloride having been omitted on the first day. Hypotension was not observed after the initial dose, and therefore enalapril was given at a dose of $5 \mathrm{mg}$ daily for the next 3 days in addition to the frusemide $80 \mathrm{mg}$ daily. The amiloride was discontinued. Plasma biochemistry on the 4th day of enalapril therapy was markedly abnormal: urea $32.3 \mathrm{mmol} / \mathrm{l}$, sodium $130 \mathrm{mmol} / \mathrm{l}$, potassium $7.4 \mathrm{mmol} / \mathrm{l}$ and creatinine $300 \mu \mathrm{mol} / \mathrm{l}$. All medication was discontinued and intermittent peritoneal dialysis started. Hypotention had not been observed following the first dose of enalapril, and blood pressure on the 4th day was $120 / 80 \mathrm{mmHg}$. Also, her central venous pressure was $+10 \mathrm{~cm}$ water above the mid-axilla. Renal function remained markedly abnormal over the next 2 weeks, at which time she suffered a severe left hemiparesis. She subsequently died of her stroke 2 weeks later. Post-mortem examination revealed normal renal arteries.

\section{Case 3}

A 59 year old man was first noted to have congestive cardiac failure secondary to coronary ischaemia in January 1986. He was commenced on frusemide $80 \mathrm{mg}$ daily, amiloride $10 \mathrm{mg}$ daily and digoxin. In October of the same year he was admitted to hospital following a deterioration of his heart failure. He was eventually discharged taking frusemide $120 \mathrm{mg}$ twice daily, enalapril $10 \mathrm{mg}$ daily and digoxin. His plasma urea and electrolytes on discharge were normal. Twelve months later, in September 1987, when reviewed, he was again in mild congestive heart failure with a raised JVP and peripheral oedema. Blood pressure was normal at $120 / 70 \mathrm{mmHg}$ lying and standing. Plasma electrolytes were: urea $7.7 \mathrm{mmol} / 1$, sodium $141 \mathrm{mmol} / 1$, potassium $3.2 \mathrm{mmol} / 1$ and creatinine $136 \mu \mathrm{mol} / 1$. Enalapril was increased to $15 \mathrm{mg}$ daily.

Two months later he was admitted as an emergency in acute renal failure with a plasma urea $97.2 \mathrm{mmol} / \mathrm{l}$, potassium $6.3 \mathrm{mmol} / 1$ and creatinine $1210 \mu \mathrm{mol} / \mathrm{l}$. Blood pressure was $110 / 75 \mathrm{mmHg}$ lying and $105 / 60 \mathrm{mmHg}$ standing. Central venous pressure was $+8 \mathrm{~cm}$ water from the mid axilla. All medication was discontinued and peritoneal dialysis instituted. His initial 24-hour urine output was $200 \mathrm{ml}$, but this rapidly rose to over 2 litres. Similarly, his renal function improved dramatically, and within 5 days his urea had fallen to $4.8 \mathrm{mmol} / 1$, potassium to $4.1 \mathrm{mmol} / 1$ and creatin- ine to $113 \mu \mathrm{mol} / \mathrm{l}$. His blood pressure following discontinuation of enalapril rose to $125 / 80 \mathrm{mmHg}$ lying and standing.

He has never exhibited proteinuria, is not diabetic, and a DTPA renogram has subsequently shown no evidence of renovascular disease.

\section{Case 4}

A 65 year old women was first seen in 1985 with congestive heart failure secondary to mitral valve disease. She was treated with frusemide $120 \mathrm{mg}$ twice daily, amiloride $10 \mathrm{mg}$ once daily and digoxin. Her symptoms were controlled until April 1988 when she was admitted to hospital with severe heart failure. She made a good response to treatment and was discharged taking the above medication plus metolazone $2.5 \mathrm{mg}$ daily and captopril $6.25 \mathrm{mg} 3$ times daily. On discharge, plasma urea was $8 \mathrm{mmol} / 1$, potassium $3.6 \mathrm{mmol} / \mathrm{l}$ and creatinine $130 \mu \mathrm{mol} / 1$.

On review in clinic 1 month later, her heart failure had deteriorated symptomatically, clinically and radiographically. Her JVP was raised, and she had both pulmonary and peripheral oedema. Her captopril dosage only was increased to $12.5 \mathrm{mg} 3$ times daily. Plasma urea and electrolytes performed on the same day were unchanged from 1 month previously. Blood pressure was 125/90 $\mathrm{mmHg}$.

One month later there had been a marked improvement in her heart failure, but a significant deterioration in her renal function. Plasma electrolytes on this occasion revealed a urea of $28.8 \mathrm{mmol} / \mathrm{l}$, potassium $4.0 \mathrm{mmol} / 1$, sodium $134 \mathrm{mmol} / 1$ and creatinine $259 \mu \mathrm{mol} / 1$. Significantly, her JVP was $4 \mathrm{~cm}$ above the sternal angle and her blood pressure was slightly lower at $115 / 60 \mathrm{mmHg}$. All her medication was left unchanged and she was reviewed 1 week later. There had been a further reduction in renal function in the absence of volume depletion or hypotension. On this occasion her urea was $34.0 \mathrm{mmol} / 1$, and creatinine $357 \mu \mathrm{mol} / 1$. On discontinuation of her captopril, renal function returned to normal within 1 month.

Subsequently, a DTPA renogram showed no evidence of renovascular disease. She is not diabetic and does not have proteinuria.

\section{Discussion}

Inhibition of the renin angiotensin system (RAS), with ACE inhibitors, is a well-established approach in the treatment of patients with congestive heart failure. ${ }^{2-7}$ Patients report an increase in well-being, and indeed may improve sufficiently to alter grading on the New York Health Association (NYHA) scale. 
The haemodynamic changes that are apparent in patients with congestive heart failure may be dramatically ameliorated by the introduction of an ACE inhibitor. Of note, ACE inhibition causes a reduction in mean arterial blood pressure, left ventricular filling pressure, mean right atrial pressure and systemic vascular resistance. ${ }^{8,9}$

Activation of the RAS in congestive heart failure may be to preserve renal function in the face of renal hypoperfusion, ${ }^{10,11}$ rather than to maintain sodium and water homeostasis or blood pressure. The preferential action of angiotensin II on the glomerular efferent arteriole maintains filtration in the presence of renal hypoperfusion. By removing this stimulus (as with an ACE inhibitor) to the efferent arteriole, one may observe a reduction in the glomerular filtration rate, despite an increase in renal plasma flow.

In addition, the sodium status of an individual is crucial to the activity of the RAS. Sodium-deplete patients (either through salt restriction or diuretic therapy) show a much greater response to inhibition of angiotension II than do sodium-replete patients. ${ }^{12,13}$

It has been suggested that glomerular filtration will fall only when 3 criteria are met: (1) renal perfusion is decreased; (2) the RAS is activated by sodium depletion; and (3) the action of angiotensin II within the kidney is blocked. ${ }^{14,15}$

In Packer's study9 of 104 patients with severe heart failure treated with either enalapril or captopril, 70 patients showed an improvement in renal function and 34 a deterioration. This deterioration was associated with (1) a significantly lower right mean atrial pressure to begin with; (2) a significantly greater reduction in mean arterial blood pressure by ACE inhibition; (3) a significant number of patients being diabetic; and (4) patients taking significantly larger doses of diuretics.

Only 9 of the 34 patients experienced a marked increase in blood urea and creatinine, and these patients showed the greatest reduction in mean right atrial pressure, mean arterial blood pressure and left ventricular filling pressure. One patient died of progressive renal insufficiency despite discontinuation of therapy.

These findings confirmed those of Pierpont $e t$ $a l .{ }^{16}$ in 1981 . They treated 9 patients with severe congestive heart failure with captopril, and noted a reduction in creatinine clearance of $25 \%$ or more in 3 patients who showed the greatest reduction in blood pressure.

Packer and colleagues ${ }^{17}$ have subsequently identified pre-existing hyponatraemia (an indication of reduced renal perfusion) as the most important predictor of which patients with heart failure will develop renal functional insufficiency on the introduction of an ACE inhibitor.

The effects of long- and short-acting ACE inhibitors on renal function in heart failure have also been addressed. One study ${ }^{18}$ compared captopril $50 \mathrm{mg} 3$ times daily with enalapril $40 \mathrm{mg}$ daily. Renal function deteriorated in the enalapril-treated but not the captopril-treated group. A second study ${ }^{19}$ comparing lisinopril (an intermediate acting ACE inhibitor) with captopril in patients with severe heart failure found that increases in blood urea and creatinine were more common in the lisinopril-treated group. In both studies, these changes were mild, did not require withdrawal of the drug, and were ascribed to the longer duration of action of the drugs.

A recent symposium ${ }^{20}$ on ACE inhibitors reviewed the safety of quinipril (an ACE inhibitor with a half-life slightly greater than that of captopril) in the treatment of hypertension and heart failure. It was noted that when quinipril was given twice daily increases in serum creatinine were as common as with enalapril therapy, whereas with a once daily regimen the incidence was much reduced and comparable to that which occurred with captopril treatment. It was proposed that longer-acting ACE inhibitors cause prolonged dilatation of the glomerular efferent arteriole and thus a persistent reduction in filtration, whereas shorter-acting ACE inhibitors allow an 'end of dose' efferent arteriolar constriction which maintains glomerular filtration.

All 4 of our patients were commenced on small doses of either enalapril or captopril following failure of diuretics to control their heart failure. In addition, all our patients exhibited signs of right heart failure (raised jugular venous pressure and peripheral oedema) as well as left, at the time of either the initial treatment with, or on increased dosage of, ACE inhibitor. None of the patients were hypovolaemic either clinically or as judged by central venous pressure readings when assessed with renal failure.

Similarly, none of our patients experienced anything other than the small expected fall in blood pressure associated with ACE inhibition. All patients had normal serum sodium levels and, although these patients may have been advised to reduce their salt intake at the onset of congestive heart failure, none of the patients had been specifically instructed to adopt a low sodium diet either prior to commencement of ACE inhibition or at any time thereafter. No patient was diabetic. Three patients had DTPA renograms performed and these showed no evidence of renovascular disease. The fourth had normal renal arteries at postmortem. No patient had evidence of underlying renal disease as manifest by proteinuria and no patient had evidence of intercurrent illness preceding the development of renal impairment. There was no evidence of recent myocardial infarction in any of the 4 patients. The rapidity of the improvement in renal function following discontinuation of 
either enalapril or captopril in cases 1,3 and 4 would favour a haemodynamic disturbance as the cause.

All of our patients developed renal insufficiency on relatively small doses of either enalapril or captopril, and none of them would appear to have been predisposed to the development of renal failure as judged by the accepted criteria (see above reference). It remains likely that the predominant reason for the renal failure in these patients was a critical fall in renal perfusion despite seemingly.

\section{References}

1. Packer, M. Identification of risk factors predisposing to the development of functional renal insufficiency during treatment with converting-enzyme inhibitors in chronic heart failure. Cardiology 1989, 76 (Suppl 2): 50-55.

2. Kramer, B.L., Massie, B.M. \& Topic, N. Controlled trial of captopril in chronic heart failure: a rest and exercise haemodynamic study. Circulation 1983, 67: 807-816.

3. Captopril Multicenter Research Group. A placebo controlled trial of captopril in refractory chronic heart failure. J Am Coll Cardiol 1983, 2: 755-763.

4. Cleland, J.G.F., Dargie, H.J., Hodsman, G.P. et al. Captopril in heart failure: a double-blind controlled trial. $\mathrm{Br}$ Heart $J$ 1984, 52: 530-535.

5. Sharpe, D.N., Murphy, J., Coxon, R. \& Hannan, S.F. Enalapril in patients with chronic heart failure; a placebo controlled, randomized, double-blind study. Circulation 1984, 70: $271-278$.

6. Franciosa, J.A., Wilen, M.M. \& Jordan, R.A. Effects of enalapril, a new angiotensin-converting enzyme inhibitor, in a controlled trial in heart failure. J Am Coll Cardiol 1985, 5: $101-107$.

7. Cleland, J.G.F., Dargie, H.J., Ball, S.G. et al. Effects of enalapril in heart failure: a double blind study of effects on exercise performance, renal function, hormones and metabolic state. Br Heart J 1985, 54: 305-312.

8. Faxon, D.P., Halperin, J.L., Creager, M.A., Gavras, H., Schick, E.C. \& Ryan, T.J. Angiotensin inhibition in severe heart failure: acute central and limb haemodynamic effects of captopril with observations on sustained oral therapy. Am Heart J 1981, 101: 548-556.

9. Packer, M., Lee, W.H., Medina, N., Yushak, M. \& Kessler, P.D. Functional renal insufficiency during long-term therapy with captopril and enalapril in severe chronic heart failure. Ann Intern Med 1987, 106: 346-354.

10. Packer, $M$. Why do kidneys release renin in patients with chronic heart failure? A nephrocentric view of converting enzyme inhibition. Am J Cardiol 1987, 60: 179-184. adequate systemic pressure, central venous expansion and lack of hyponatraemia. Whilst we fully agree with the accepted criteria for detecting susceptible patients, all patients on diuretics and converting enzyme inhibitors, with severe congestive heart failure, should be closely monitored and have ACE inhibitors withdrawn, or the dosage reduced, at the earliest signs of renal insufficiency, as a potentially fatal situation can be readily avoided.

11. Packer, M. Interaction of prostaglandins and angiotensin II in the modulation of renal function in chronic heart failure. Circulation 1988, 77 (Suppl. 1): 64-73.

12. Bravo, E.L. \& Tarazi, R.C. Converting enzyme inhibition with an orally active compound in hypertensive man. Hypertension 1979, 1: 39-46.

13. Murphy, B.F., Whitworth, J.A. \& Kincaid-Smith, P. Renal insufficiency with combinations of angiotensin converting enzyme inhibitors and diuretics. $\mathrm{Br} \mathrm{Med} J$ 1984, 288: 844-845.

14. Hall, J.E., Guyton, A.C.,, Jackson, T.E., Coleman, T.G., Lohmeier, T.E. \& Trippodo, N.C. Control of glomerular filtration rate by renin-angiotensin system. Am J Physiol 1977, 233: F366-372.

15. Lohmeier, T.E., Cowley, A.W. Jr., Trippodo, N.C., Hall, J.E. \& Guyton, A.C. Effects of endogenous angiotensin II on renal sodium excretion and renal haemodynamics. $\mathrm{Am} J$ Physiol 1977, 233: F388-395.

16. Pierpont, G.L., Francis, G.S. \& Jay, N.C. Effect of captopril on renal function in patients with congestive heart failure. $\mathrm{Br}$ Heart J 1981, 46: 522-527.

17. Packer, M., Lee, W.H., Kessler, P.D., Medina, N., Yushak, M. \& Gottlieb, S.S. Identification of hyponatraemia as a risk factor for the development of functional renal insufficiency during converting enzyme inhibition in severe chronic heart failure. J Am Coll Cardiol 1987, 10: 837-844.

18. Packer, M., Lee, W.H., Yushak, M. \& Medina, R.N. Comparison of captopril and enalapril in patients with severe chronic heart failure. $N$ Engl J Med 1986, 315: 847-853.

19. Powers, E.R., Chiaramida, A., DeMaria, A.N. et al. A double blind comparison of lisinopril with captopril in patients with symptomatic congestive heart failure. J Cardiovasc Pharmacol 1987, 9 (Suppl. 3): S82-88.

20. Frank, G. Does the duration of angiotensin converting enzyme inhibitors affect their safety and adverse effects? $J$ Hyperten 1989, 7 (Suppl. 5): S17-S22. 